\title{
Letter to the editor: the nonnegligible effect of neoadjuvant therapy for patients with borderline resectable pancreatic ductal adenocarcinoma
}

\author{
Li Wang ${ }^{1}$, Xin Zhang ${ }^{2}$, Yanrong Lu ${ }^{1}$, Bole Tian ${ }^{1}$ \\ ${ }^{1}$ Department of Pancreatic Surgery, West China Hospital, Sichuan University, Chengdu, China; ${ }^{2}$ West China School of Medicine, Sichuan \\ University, Chengdu, China \\ Correspondence to: Professor Bole Tian. Department of Pancreatic Surgery, West China Hospital, Sichuan University, 37\# Guoxue Alley, Chengdu, \\ China. Email: tianbole@163.com. \\ Response to: Wang J, Lyu SC, Zhou L, et al. Prognostic analysis of pancreatic carcinoma with portal system invasion following curative resection. \\ Gland Surg 2021;10:35-49.
}

Submitted Jun 08, 2021. Accepted for publication Jun 30, 2021.

doi: $10.21037 / g s-21-379$

View this article at: https://dx.doi.org/10.21037/gs-21-379

To date, R0 resection still remains the standard curative approach for pancreatic ductal adenocarcinoma (PDAC). Due to multiple factors including technical refinements, mortality in pancreatic surgery has dropped below $3 \%$. In contrast, postoperative morbidity following pancreatectomy occurs in more than one third of all patients undergoing pancreatectomies (1). Numerous articles on improving the outcomes of these patients have been published these years. Recently, we read with great interest the article by Wang and colleagues regarding the related factors affecting the prognosis of pancreatic carcinoma with portal venous system invasion (2). We congratulate the authors for this interesting study. They evaluated the prognosis of 118 pancreatic cancer patients with portal venous system invasion who underwent curative resection, and found that the venous invasion depth was an independent risk factor for the prognosis of patients with PDAC. Considering the borderline resectable feature of the patients included in this study, we paid some additional attention to the content about neoadjuvant therapy (NAT) which was recommended for this kind of patients by the National Comprehensive Cancer Network (NCCN) guidelines. And we have few questions and remarks.

The authors' results are interesting and remarkable, because they included a very important sub-population of patients with borderline resectable PDACs. They stratified the depth of portal venous invasion into Adventitia, Muscle layer, and Whole layer, and found that the invasion depth was an independent risk factor for the prognosis of these patients. Meanwhile, 47 of the included patients have adjuvant chemotherapy during follow-up period. However, unexpectedly, they didn't provide any data about preoperative NAT which was advised for borderline resectable PDAC patients by the guidelines. As the author mentioned in the discussion section, it still remains controversial on the indication of neoadjuvant therapy. The overall effective rate of chemotherapy for pancreatic cancer is less than $30 \%$, while the effect of this regimen is even worse for Chinese patients (2). As a result, the extensive adoption of NAT may cause delays in the timing of surgery. Even so, if they could show the proportion of NAT in their cohort and the corresponding prognostic effects, the readers may understand and cite the results more precisely.

On the other hand, we notice they have mentioned the postoperative morbidity of the 118 patients, including biochemical fistula $(\mathrm{n}=10)$ and clinical postoperative pancreatic fistula $(n=5)$. Recently, we have performed a brief meta-analysis, which has not been published elsewhere, just to elucidate the effect of NAT on preventing postoperative pancreatic fistula in patients with PDAC. Indeed, several recent studies have reported postoperative clinical pancreatic fistula with or without NAT preoperatively (3-9). And the pooled results of these studies demonstrated that the administration of NAT had a beneficial effect on reducing the risk of clinical pancreatic 


\begin{tabular}{|c|c|c|c|}
\hline \multirow{2}{*}{$\begin{array}{l}\text { Study } \\
\text { ID }\end{array}$} & & \multicolumn{2}{|r|}{$\%$} \\
\hline & & OR $(95 \% \mathrm{Cl})$ & Weight \\
\hline Takahashi 2011 & 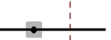 & $0.21(0.05,0.85)$ & 4.63 \\
\hline Satoi 2012 & & $0.16(0.01,3.16)$ & 1.53 \\
\hline Araujo 2013 & & $0.64(0.10,4.16)$ & 1.36 \\
\hline Marchegiani 2018 & $\longrightarrow$ & $0.56(0.26,1.24)$ & 8.93 \\
\hline Hank 2019 & $\longrightarrow$ & $0.24(0.13,0.46)$ & 24.17 \\
\hline Lof 2019 & $\longrightarrow$ & $0.35(0.15,0.80)$ & 9.71 \\
\hline Dahdaleh 2020 & $\rightarrow$ & $0.52(0.37,0.72)$ & 49.68 \\
\hline Overall (I-squared $=11.6 \%, P=0.341)$ & 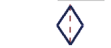 & $0.42(0.33,0.54)$ & 100.00 \\
\hline
\end{tabular}

Figure 1 Forest plots of the effects of NAT on clinical pancreatic fistula for PDAC patients. NAT, neoadjuvant therapy; PDAC, pancreatic ductal adenocarcinoma; OR, odds ratio; CI, confidence interval.

fistula (grade B and C) for patients with surgical treated pancreatic cancer $(\mathrm{OR}, 0.42 ; 95 \%$ confidence interval, 0.33 to $0.54 ; \mathrm{P}<0.001$ ) (Figure 1). However, none of these studies including Chinese patients. Thus, we are curious about the corresponding results of this study which reflect the outcomes of Chinese PDAC patients.

Indeed, by reducing tumor bulk and involvement of nearby structures, NAT is increasingly being utilized in borderline resectable and locally advanced pancreatic cancer to increase resectability and improve margin negative resection rates, but with a risk of delays in the timing of surgery and tumor progression. Thus, it still remains controversial among scholars, especially for surgeons. Interestingly, there is mounting evidence indicating that NAT is able to reduce the risk of pancreatic fistula besides its fundamental role in downstaging pancreatic tumors and improving survival outcomes, which was confirmed by the pooled results indicated above. Theoretically, this may be explained by the pancreatic fibrosis and lobular atrophy, and the subsequent harder gland texture and poorer exocrine function of the pancreas following NAT (10).

In conclusion, we congratulate the authors for the remarkable study, which add significant value and information to the debate on the surgical strategy and relative prognosis of patients with borderline resectable PDAC. Meanwhile, further discussion and studies are needed to assess the effects of NAT for Chinese PDAC patients.

\section{Acknowledgments}

Funding: This study was supported by the post-doctor research project, West China Hospital, Sichuan University (2020HXBH046).

\section{Footnote}

Provenance and Peer Review: This article was a standard submission to the journal. The article did not undergo external peer review.

Conflicts of Interest: All authors have completed the ICMJE uniform disclosure form (available at https://dx.doi. org/10.21037/gs-21-379). The authors have no conflicts of interest to declare.

Ethical Statement: The authors are accountable for all aspects of the work in ensuring that questions related to the accuracy or integrity of any part of the work are appropriately investigated and resolved.

Open Access Statement: This is an Open Access article distributed in accordance with the Creative Commons Attribution-NonCommercial-NoDerivs 4.0 International License (CC BY-NC-ND 4.0), which permits the noncommercial replication and distribution of the article with the strict proviso that no changes or edits are made and 
the original work is properly cited (including links to both the formal publication through the relevant DOI and the license). See: https://creativecommons.org/licenses/by-ncnd/4.0/.

\section{References}

1. Beger HG, Mayer B. Early postoperative and late metabolic morbidity after pancreatic resections: An old and new challenge for surgeons - A review. Am J Surg 2018;216:131-4.

2. Wang J, Lyu SC, Zhou L, et al. Prognostic analysis of pancreatic carcinoma with portal system invasion following curative resection. Gland Surg 2021;10:35-49.

3. Araujo RL, Gaujoux S, Huguet F, et al. Does pre-operative chemoradiation for initially unresectable or borderline resectable pancreatic adenocarcinoma increase postoperative morbidity? A case-matched analysis. HPB (Oxford) 2013;15:574-80.

4. Dahdaleh FS, Naffouje SA, Hanna MH, et al. Impact of Neoadjuvant Systemic Therapy on Pancreatic Fistula Rates Following Pancreatectomy: a Population-Based Propensity-Matched Analysis. J Gastrointest Surg 2021;25:747-56.

5. Hank T, Sandini M, Ferrone CR, et al. Association

Cite this article as: Wang L, Zhang X, Lu Y, Tian B. Letter to the editor: the nonnegligible effect of neoadjuvant therapy for patients with borderline resectable pancreatic ductal adenocarcinoma. Gland Surg 2021;10(7):2340-2342. doi: 10.21037/ gs-21-379
Between Pancreatic Fistula and Long-term Survival in the Era of Neoadjuvant Chemotherapy. JAMA Surg 2019;154:943-51.

6. Lof S, Korrel M, van Hilst J, et al. Impact of Neoadjuvant Therapy in Resected Pancreatic Ductal Adenocarcinoma of the Pancreatic Body or Tail on Surgical and Oncological Outcome: A Propensity-Score Matched Multicenter Study. Ann Surg Oncol 2020;27:1986-96.

7. Marchegiani G, Andrianello S, Nessi C, et al. Neoadjuvant Therapy Versus Upfront Resection for Pancreatic Cancer: The Actual Spectrum and Clinical Burden of Postoperative Complications. Ann Surg Oncol 2018;25:626-37.

8. Satoi S, Toyokawa H, Yanagimoto H, et al. Neo-adjuvant chemoradiation therapy using S-1 followed by surgical resection in patients with pancreatic cancer. J Gastrointest Surg 2012;16:784-92.

9. Takahashi H, Ogawa H, Ohigashi H, et al. Preoperative chemoradiation reduces the risk of pancreatic fistula after distal pancreatectomy for pancreatic adenocarcinoma. Surgery 2011;150:547-56.

10. Chatterjee D, Katz MH, Rashid A, et al. Pancreatic intraepithelial neoplasia and histological changes in nonneoplastic pancreas associated with neoadjuvant therapy in patients with pancreatic ductal adenocarcinoma. Histopathology 2013;63:841-51. 